\title{
Título de la síntesis: Trayecto formativo de educación ambiental para la gestión de los bienes comunes de la naturaleza
}

Titulo completo de la tesis de posgrado: Educación Ambiental, una estrategia para la generación de conocimientos orientados a la gestión sustentable de los bienes comunes de la naturaleza. El caso del «Parque ecosistémico El rincón de Santa Lucía», Canelones Uruguay

Palabras clave: Educación ambiental. Cartografías ambientales participativas. Bienes comunes de la naturaleza. Gestión ambiental sustentable.

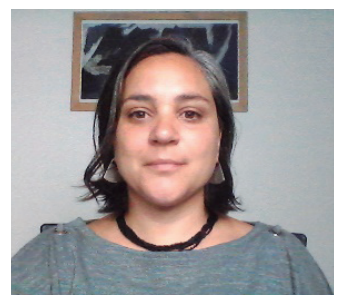

Lucía Eluén Morixe

leluen@fcien.edu.uy

ORCID 0000-0002-6082-5819

Directores de tesis: Marcel Achkar Borras; Ana Domínguez Sandoval

Institución donde se realizó el trabajo de tesis: Laboratorio de Desarrollo Sustentable y Gestión Ambiental del Territorio del Instituto de Ecología y Ciencias Ambientales de la Facultad de Ciencias - Universidad de la República. Montevideo, Uruguay

Fecha de defensa de la tesis: 07.08.2020

Acceso a texto completo:

http://repositorio.cfe.edu.uy/handle/123456789/1125

Nombre de la Carrera de posgrado: Maestría en Educación Ambiental

\section{Institución y/o programa donde emitió el título:}

Facultad de Ciencias -Universidad de la República. Consejo de Formación en Educación- Administración Nacional de Educación Pública.

\section{Síntesis del trabajo}

En esta tesis nos posicionamos desde la Educación Ambiental Crítica (EA) que establece el compromiso con la construcción del saber ambiental y busca empoderar a las comunidades locales en la apropiación y control de los bienes comunes de la naturaleza. Los procesos de EA permiten realizar una lectura crítica del territorio, al analizar la información existente y construir nuevos saberes. Por otra parte, las metodologías ambientales participativas, son herramientas de empoderamiento de los agentes locales en la defensa de los bienes comunes de la naturaleza. Las técnicas de mapeo participativo asisten a las comunidades locales, para representar espacialmente sus saberes, intereses y valoraciones ambientales. Centradas en la creación de análisis espaciales por parte de agentes locales, a través de la representación espacial de los conocimientos empíricos y técnicos locales, es posible identificar modelos de valoración, apropiación y gestión de un territorio para reconocer en la comunidad los bienes naturales y culturales e iniciativas para su manejo sustentable, así como priorizar las tensiones ambientales de uso y gestión. Por lo que las técnicas de mapeo participativo permiten la sistematización, evaluación y valoración de la información existente o generada sobre la naturaleza para la toma de decisiones que permitan, por ejemplo, establecer lineamientos para un plan de gestión ambiental.

La integración de la EA con metodologías de mapeo participativo, genera y pone a disposición información ambiental de calidad para la toma de decisión de modo 
informado y calificado. Esto permite orientar el proceso de EA en la gestión ambiental hacia la producción y adquisición de conocimientos y habilidades, y desarrollar actitudes para la participación que promueva la acción colectiva. Lo que posibilita la construcción de ciudadanía y asegura la gestión ambiental sustentable de los territorios.

Se realizó el estudio de caso en el parque «El Rincón de Santa Lucía», ubicado en el departamento Canelones, en la cuenca del río Santa Lucía. Es un área de gestión que se proyecta por parte del gobierno departamental, como parque público y área de conservación, bajo un modelo de gestión sustentable para el desarrollo local. A nivel nacional forma parte del área natural protegida "Humedales de Santa Lucía» del Sistema Nacional de Áreas Protegida bajo la categoría «Área protegida con recursos manejados». Además, es una zona de relevancia para la gestión ambiental al estar sujeta a medidas de protección de fuentes de agua potable, que abastecen a la mayor parte de la población del país. A nivel local, se destaca también por su valor cultural, actualmente el área presenta diversos usos de los bienes comunes de la naturaleza para fines de subsistencia: extracción de madera, arena, tierra y paja; pastoreo de ganado y; servicios educativo y recreativo. Varios son los agentes territoriales del área: gestores en distintos niveles de gobierno, organizaciones de la sociedad civil, usuarios de los recursos de uso compartido, población local, investigadores y visitantes.

El objetivo de esta investigación fue fortalecer el proceso de EA, mediante la generación de nuevos conocimientos con los agentes territoriales presentes en el área, que contribuyan con la gestión sustentable de los bienes comunes de la naturaleza del parque El Rincón de Santa Lucía. Para ello se propuso orientar al proceso de EA en la elaboración de lineamientos para un plan de gestión ambiental que contemple el uso e intereses de los diversos agentes territoriales presentes en el área y que contribuya al modelo de gestión sustentable y uso diferencial propuesto por el gobierno de Canelones; zonificar y caracterizar el área en unidades biofísicas; identificar los agentes vinculados a los usos de los bienes comunes de la naturaleza y gestión del área; identificar y caracterizar los usos del suelo actuales y construir un índice de distribución espacial de la vulnerabilidad ambiental del parque El Rincón de Santa Lucía.

Este trabajo aporta un posible trayecto que transita por una secuencia de finalidades formativas de EA para apoyar proyectos políticos sustentables. Específicamente en la planificación de medidas de uso y gestión de los bienes comunes de la naturaleza. Al tiempo que reconoce los derechos territoriales/territorialidades locales y propone la generación de lineamientos y acciones para el fortalecimiento de las políticas públicas. El trayecto está diseñado de modo que a partir de la identificación una necesidad común por los agentes territoriales, se generan conocimientos para la planificación e implementación de acciones, que tienen por finalidad aumentar la capacidad de gestión y participación en los procesos de GA.

Se avanza en la integración de saberes y generación de conocimiento sobre factores interdependientes que permiten abordar el vínculo sociedad - naturaleza. La triangulación de técnicas, cualitativas y cuantitativas de recolección y análisis de información, en base a trabajo de laboratorio y de campo permitió identificar los agentes sociales vinculados a la apropiación y gestión de los bienes naturales de uso común, y elaborar un sistema de información geográfico a escala local con un set de cartografías ambientales sobre: el estado biofísico del área; los usos del suelo e índice de vulnerabilidad ambiental.

Las cartografías ambientales evidencian distintas formas de apropiación del territorio, al identificar espacialmente las representaciones sociales, los atributos del ambiente, y la superposición de intereses. La generación de un índice de vulnerabilidad ambiental validado científicamente y de fácil interpretación, permite ser utilizado en diversos ámbitos para visualizar diferentes alternativas ante los problemas identificados. La estrategia de construcción participativa permite que las cartografías digitales integren los diversos saberes locales, técnicos y académicos; las historias de uso y; los acuerdos legales y consuetudinarios al análisis espacial para orientar a las políticas públicas, habilitando espacios preparatorios a la definición de estrategias de acción comunitaria.

El trayecto formativo propone una estrategia para trabajar con colectivos diversos, con conflictos de intereses y sin acuerdos explícitos, al proponer un abordaje para mejorar y superar las limitaciones de las realidades ambientales complejas del área sobre la gestión de los bienes comunes de la naturaleza. La finalidad formativa propuesta busca transitar hacia el empoderamiento ambiental de las comunidades que contribuya a proyectos políticos de sustentabilidad ambiental que integren conservación y provisión de bienes a largo plazo. El vínculo establecido hasta el momento permitió la identificación de temas emergentes, orientaciones y medidas generales para la transformación de los sistemas ambientales en escenarios sustentables. Las instancias de observación participante junto con las 
entrevistas realizas, permitieron identificar la necesidad de generar cartografías sobre el estado ambiental de los bienes de la naturaleza existentes en el área; y construir mapas que contienen información sobre la distribución espacial de las actividades antrópicas, clasificación de zonas según niveles de vulnerabilidad ambiental, las medidas de manejo existentes y los principales problemas identificado. Insumos base para la proyección de acciones comunitarias de sustentabilidad. El proceso histórico que ha acontecido en el parque El Rincón de Santa Lucía desde que fue donado para el uso estatal y público, es un proceso exitoso según los mapas obtenidos. Lo que afirma el potencial para avanzar en la implementación de estrategias que permitan dinamizar, ampliar y aumentar la capacidad de uso sustentable del sistema ambiental. El potencial del área muestra grados de libertad para mejorar las condiciones socioeconómicas y calidad de vida de la población que hace uso del área con fines de subsistencia.

El Rincón de Santa Lucía presenta las condiciones necesarias para continuar los procesos de gestión del espacio público y ampliación del espacio político de participación. En un contexto de marcos normativos favorables de políticas ambientales y educativas, el estado ambiental del área con potencial de recuperación; la integración y convergencia de ámbitos en un territorio concebido como espacio público de uso común de los recursos naturales; y la apertura para el diálogo por parte de los agentes territoriales. La EA, y el trayecto formativo, se proponen como un campo de acción desde donde ensayar la planificación de mecanismos y espacios de cogestión. Los mapas ambientales del parque El Rincón de Santa Lucía, muestran que la gestión ambiental sustentable demanda la participación de los actores tanto para reconocer sus bienes comunes como para tomar decisiones y gestionarlos.

La integración de la EA con mapeo participativo en las políticas públicas ambientales, mediante el diseño e implementación de un trayecto formativo contextualizado para un proceso de educación no formal y dirigido a adulto, permite contribuir al diseño de los espacios de debate y negociación, con estrategias pedagógicas específicas de formación de ciudadanía para fortalecer las redes de gestión de los bienes comunes. Por lo que la EA cobra un rol relevante en el diseño de estrategias de enseñanza-aprendizajecreación de proyectos políticos orientados a profundizar los procesos democráticos y el desarrollo de territorialidades identitarias en la gestión de asuntos públicos, que fortalezca la capacidad social para establecer una nueva ética que reconceptualice el sistema ambiental en la gestión ambiental y habilite construcciones de sustentabilidad. 